\title{
Deterjan Bazlı Çamaşır Makinesi Atıksuyunun YDA ve EoL Analizi ile Değerlendirilmesi
}

\author{
Hakan Çelebi ${ }^{*}$, Tolga Bahadır ${ }^{2}$, İsmail Şimşek ${ }^{3}$, Şevket Tulun ${ }^{4}$ \\ ${ }^{1}$ Aksaray Üniversitesi, Mühendislik Fakültesi, Çevre Mühendisliği Bölümü, Aksaray, Türkiye (ORCID: 0000-0002-7726-128X), hakanaz.celebi@gmail.com \\ ${ }^{2}$ Aksaray Üniversitesi, Mühendislik Fakültesi, Çevre Mühendisliği Bölümü, Aksaray, Türkiye (ORCID: 0000-0001-9647-0338), tolgabahadir61@ gmail.com \\ ${ }^{3}$ Aksaray Üniversitesi, Mühendislik Fakültesi, Çevre Mühendisliği Bölümü, Aksaray, Türkiye (ORCID: 0000-0003-1950-5159, ismailsimsek@ aksaray.edu.tr \\ ${ }^{4}$ Aksaray Üniversitesi, Mühendislik Fakültesi, Çevre Mühendisliği Bölümü, Aksaray, Türkiye (ORCID: 0000-0002-0570-7617), sevkettulun@gmail.com
}

(İlk Geliş Tarihi 11 Kasım 2020 ve Kabul Tarihi 18 Ocak 2021)

(DOI: $10.31590 /$ ejosat.824474)

ATIF/REFERENCE: Çelebi, H., Bahadır, T., Şimkek, İ., \& Tulun, T. (2021). Deterjan Bazlı Çamaşır Makinesi Atıksuyunun YDA ve EoL Analizi ile Değerlendirilmesi. Avrupa Bilim ve Teknoloji Dergisi, (21), 275-284.

\section{$\ddot{O} \mathbf{z}$}

Çevre kirliliği çalışmaları, tüm dünyada özellikle atıksuyun yapısında yer alan deterjan sorununun hızla arttığını göstermiştir. Çamaşır yıkamadan kaynaklı atıksularda bunlardan biri olup çamaşır makinesi atıksuyu, yüksek konsantrasyonlu deterjanlar, sürfaktan, fosfat, askıda katı maddeler, yağ, renk vb. kirleticileri içeren kentsel atıksuyun bir parçası olarak karşımıza çıkmaktadır. Bu çalışmada, deterjanların salınımı hakkında güvenilir veriler elde etmek ve çamaşır makinesi atıksularının olası çevresel etkilerini belirlemek amacıyla, ev tipi çamaşır makinesi kullanılarak giysiler üzerinde gerçek ölçekte çamaşır makinesinde yıkama denemeleri yapılmıştır. Yıkama işlemi sonunda atıksular iki farklı deterjan için ayrı ayrı toplanıp analizler gerçekleştirilmiştir. Bu sayede bor içeriğine sahip deterjanın çevresel etki boyutu da incelenmiştir. Ayrıca, deterjanlar ve çamaşır makinesi atıksuyu için yaşam döngüsü ve EoL diyagramları temelinde çevresel değerlendirmeler yapılmıştır. Sonuçta, yapılan atıksu analizlerine ve EoL diyagramına göre bor içeriğine sahip deterjanın yüzey aktif madde (MBAS) $(104.1 \mathrm{mg} / \mathrm{L})$ ve fosfat $(1.506 \mathrm{mg} / \mathrm{L})$ açısından diğer deterjana $(\mathrm{MBAS}=220.4$ $\mathrm{mg} / \mathrm{L}$, fosfat $=8.863 \mathrm{mg} / \mathrm{L}$ ) göre daha iyi olduğu ortaya konmuştur.

\section{Evaluation of Detergent-Based Washing Machine Wastewater by LCA and EoL Analysis}

\begin{abstract}
Environmental pollution studies have shown that the detergent problem in the structure of wastewater is increasing rapidly all over the world. Washing machine wastewater, high concentration detergents, surfactant, phosphate, suspended solids, oil, colour, etc. It appears as a part of urban wastewater containing pollutants. In this study, in order to obtain reliable data on the release of detergents and to determine the possible environmental effects of washing machine wastewater, real-scale washing trials were carried out on clothes using a household washing machine. At the end of the washing process, wastewater was collected separately for two different detergents and analyzed. Thus, the environmental impact of the detergent with boron content was also examined. In addition, environmental assessments were made for detergents and washing machine wastewater on the basis of the life cycle and EoL diagrams. As a result, according to the wastewater analysis and EoL diagram, the detergent with boron content in terms of surfactant $(104.1 \mathrm{mg} / \mathrm{L})$ and phosphate $(1.506 \mathrm{mg} / \mathrm{L})$ compared to the other detergent $(\mathrm{MBAS}=220.4 \mathrm{mg} / \mathrm{L}, \mathrm{phosphate}=8.863 \mathrm{mg} / \mathrm{L}) \mathrm{proved}$ to be better.
\end{abstract}

Keywords: Washing machine wastewater; Detergent; LCA; EoL, Pollution

*Sorumlu Yazar: hakanaz.celebi@gmail.com 


\section{Giriş}

Su kaynakları bol, ama dengesiz bir şekilde dağılmış durumdadır; yeryüzünde bulunan suyun \% 97'si denizler ve okyanuslarda, \% 2.97'si kutup buzullarında, geri kalan \% 0.03 'ü yüzey sularındadır (Lade \& Gbagba, 2018). Bu sayısal değerler doğrultusunda su, yaşamın her alanında bulunan vazgeçilmez bir kaynak olmakla birlikte, nitel ve nicel sınırlamalara sahip hassas ve sınırlı bir bileşendir. Depremler, volkanik patlamalar veya firtınalar gibi doğal olaylar suyu kirletebilirken, kirlilik oluşturan nedenlerin çoğu insan faaliyetlerinden kaynaklanmaktadır. Oldukça önemli bir küresel sorun olan su kirliliğinin kaynakları noktasal veya dağınık nitelikte olup, evsel ve endüstriyel atıksular en önemli kirlilik grubunu oluşturmaktadır. Nüfus yoğunluğunun, şehirleşmenin, endüstrileşmenin ve evsel su arzının hızla artmasıyla birlikte atıksu üretim miktarı da aynı oranda artmaktadır. İnsan faaliyetleri tarafından günlük olarak üretilen ortalama atıksu hacmi, evdeki su miktarının mevcudiyetine, kültürel düzeye/türe, suyun maliyetine ve ekonomik koşullara bağlıdır (Boulay vd., 2015). Özellikle evlerde farklı amaçlarla kullanılan sular karışık olarak kanalizasyon sistemlerine verilmektedir. Ancak bu suların her birinin kirlilik yükü birbirinden farklı olup arıtma tesislerine ek kirlilik yükü oluşturabilmektedir.

Evlerde günlük hayat içerisinde çamaşırların yıkanması yoğun olarak gerçekleştirilmekte olup, bilinçli çevre düzenlemelerinin yapılmadığı ve uygulanmadığı bir alandır. Çamaşır yıkama kaynaklı katı ve özellikle sıvı atıklar, giysilerin içindeki kir, yağ, toz ve diğer kirletici gruplarının giderilmesinde deterjan ve sabun kullanımı ile ortaya çıkmaktadır (Boulay vd., 2015; Olabode.H vd., 2019). Evsel ve ticari çamaşır makinelerinden kaynaklanan atıksuların özellikleri, kullanılacak deterjanların türüne, yıkama yöntemlerine ve tekniklerine bağlı olarak farklılık gösterebilmektedir (Olabode.H vd., 2019). Atıksu salınımlarının nitelikleri, hane halkı veya işyeri kaynağına bağlı olarak bölgeden bölgeye değişmektedir. Çamaşır makinesinden kaynaklanan atıksu, yüksek konsantrasyonlu deterjanlar, askıda katı maddeler, yağ, renk vb. içeren kentsel atıksuyun (yaklaşık \%10'u) bir parçasıdır (Olabode.H vd., 2019; Tripathi \& Khan, 2019). Tipik olarak, çamaşır makinesi atıksuları, tekstil ürünlerinin tipine bağlı olarak 1200-20000 mg/L kimyasal oksijen ihtiyacı (KOİ) değerlerine sahiptir. Çamaşır makinesi atıksuyunun karakterizasyonu ve çevresel boyutu konusunda çok az çalışma yapılmıştır (Tripathi \& Khan, 2019). Çoğunlukla literatürde bu atıksuların arıtımı üzerine çalışmalar daha yoğun gerçekleştirilmiştir (Ashfaq \& Qiblawey, 2018; Siswoyo vd., 2019; Veli vd., 2019). Bu nedenle aşağıdaki noktaları hedef alan bir araştırma çalışması yapılmıştır.

1. Çamaşır yıkamada kullanılan su kalitesi, çamaşır makinesi kullanım şekli, deterjanlar ve diğer malzemelerin tespit edilmesi,

2. Çamaşır makinesi ve deterjanlar için yaşam döngüsü diyagramı hazırlanması,

3. Çalışma alanındaki tipik çamaşır makinelerinde üretilen atıksuların laboratuvar ölçekli analizlenmesi ve değerlendirilmesi,

4. Çamaşır makinesi atıksularının yaşam döngüsü analizi (YDA) kapsamında İngilizce'de hayatın sonu anlamına gelen "end of life" (EoL) diyagramının oluşturulması ve atıksuların çevresel etki potansiyelinin değerlendirilmesi.

\section{Deterjan Tanımı}

Deterjanlar, evsel ve endüstriyel faaliyetler için yoğun olarak tüketilen önemli temizlik bileşikleridir. Geniş uygulamaları nedeniyle, deterjanlar daha yüksek kalite ve çevre standartlarını karşılamak için sürekli olarak geliştirilmektedir. Deterjanlar, uzun lipofilik hidrokarbon gruplarının sonunda polar veya yüklü hidrofilik gruplar içeren amfipatik moleküllerdir. Deterjanlar yani yüzey aktif maddeler genellikle evsel ve endüstriyel temizlik uygulamalarına göre sert yüzey temizleyici, çamaşır deterjanı ve bulaşık deterjanı olarak sınıflandırılabilirler (Dai vd., 2019). Düşük konsantrasyonlarda, deterjanlar suda monomer olarak bulunurlar ve bir deterjanın performansı deterjan konsantrasyonuna, iyonik güce, alkil zincirinin uzunluğuna, suyun pH'sına, organik katkı maddelerin varlığına, saflık ve sıcaklık faktörlerine bağlı olarak değişmektedir. Son yıllarda, sentetik deterjanların kullanımı, özellikle dünyada, çevre ve halk sağlığı üzerinde çeşitli etkilere neden olmuştur. Deterjanlar, evsel kanalizasyon sistemleriyle alıcı su ortamlarına yayıldığında yapay ötrofikasyona neden olan ve balıkçılığı olumsuz etkileyen polifosfatlar açısından zengin bileşiklerdir. Deterjanların formülasyonunda bulunan yüzey aktif madde, biyolojik olarak parçalanamayan ve çeşitli çevresel etkilere neden olan alkil benzen sülfonat (ABS) bileşiğidir. Günümüzde ise ABS yerine biyolojik olarak parçalanabilir ve çevrede salınımları daha kısa süren lineer alkilbenzen sülfonat (LAS) ve sodyum laril sülfat (SLS) yüzey aktif maddeleri kullanılmaya başlanmıştır. Deterjanlar, temizleme gücüne sahip sentetik organik kimyasallardan (sürfaktanlar) türetilen bileşiklerdir. Bunlar anyonik, katyonik ve iyonik olmayan olarak sinıflandırılırlar (Dai vd., 2019; Jardak vd., 2016).

\section{Yaşam Döngüsü Analizi (YDA)}

YDA, bir ürün ya da sürecin yaşam döngüsü boyunca hammadde aşamasından farklı çevre ortamlarına ulaşıncaya kadar geçen süreçleri içeren ve çevresel etkileri bütünleşik değerlendiren analitik bir metotdur. YDA metodolojisi tüm sektörlerde bir ürünün veya sürecin çevresel sürdürülebilirliğini ve etki düzeyini tespit etmek için yaygın olarak kullanılmaktadır (Bianchetti vd., 2015; EPA, 2010; Giagnorio vd., 2017; TSE EN ISO 14040, 2007). YDA ilk olarak 1960'larda gündem olmuş daha sonrasında ise Uluslararası Standartlar Örgütü (ISO) 14040 serisinde standarta oturtulmuştur (Şekil 1) (Ordu, 2017). Yapılan çalışmalar ve değerlendirmeler, YDA değerlendirmesinde, ORWARE, SimaPro, MARTES, TEAM by, Ecobilan, UMBERTO, LCAiT, SiSOSTAQUA, BioWin*, STAN*, WWEST, BEAM, GaBi 6 ve GEMIS modellerinin sıklıkla tercih edildiğini göstermektedir (Yapıcıŏlu \& Demir, 2017). Bu çalışmada SimaPro modellemesinden faydalanılmıştır. Ayrıca çamaşır makinesi atıksularının etki düzeylerinin dağılımını belirlemek ve çamaşır makinesi atıksularının en etkili çevre sorunlarını tespit etmek için CalcPlot3D modelleme yazılımı kullanılmıştır. ISO tarafindan özetlenen YDA, beşikten mezara veya beşikten kapıya tüm yaşam döngüsü boyunca ürünlerin veya süreçlerin çevresel performanslarını değerlendirmek için yaygın olarak kullanılmaktadır. TSE EN ISO 14040 ile tanımlanan YDA Metodolojisi 4 temel ilke doğrultusunda değerlendirilmektedir.

1. Amaç ve kapsam tanımı: Kapsam belirleme adımı, araştırmanın amacını ve sınırlarını ele alarak sonuçları ortaya koymaktadır. $\mathrm{Bu}$ aşamada, hangi süreçlerin ve çevresel risklerin dâhil edileceğini tanımlar. 
2. Envanter analizi: YDA'nın veri toplama bölümü envanter toplanması ve değerlendirilmesini kapsamaktadır. Envanterlerin toplanması için ise genellikle Ecoinvent olarak bilinen yaşam döngüsü envanter veritabanı ve diğer uygulamalar tarafindan sağlanır.

3. Etki değerlendirmesi: Envanter verileriyle ilişkili iklim değişikliği, gürültü, asidifikasyon, ötrofikasyon doğal kaynakların tüketimi, ekotoksisite ve insan toksisitesi gibi çevresel etkileri analiz etmek ve etki seviyesini karakterize etmek için kullanılan yöntemdir.

4. Yorum: Envanter analizi ve etki değerlendirmesinden elde edilen sonuçlar özetlenmekte, çalışma için sonuçlar ve öneriler getirilmektedir.

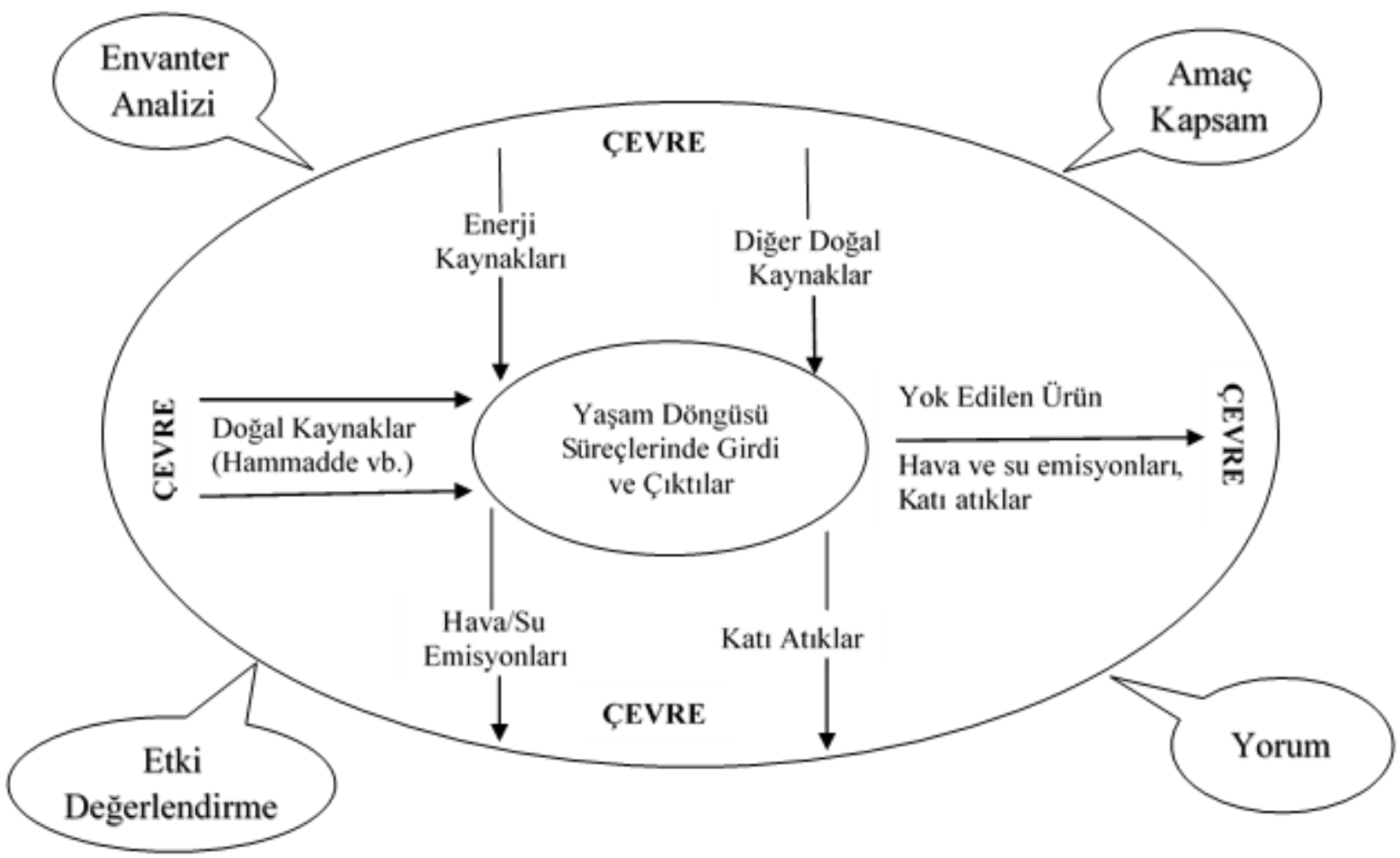

Şekil 1. YDA Yönteminin 4 Temel İlkesi ve YDA Süreçlerinde Girdi ve Çıktılar (Ordu, 2017)

\section{EoL (End of Life) Kavramı}

Sürdürülebilirlik ve ekolojik çevre tanımları ile birlikte üretimlerde daha hassas uygulamalar yapılmaktadır. Ürünlerin ve proseslerin çevresel etki düzeylerinin önemli olduğu şu günlerde işletmeler farklı minimizasyon yolları (YDA, Endüstriyel simbiyoz, sıfır atık vb.) aramaktadırlar. Bir ürünün hammadde aşamasından başlayarak, tüm üretim süreçlerinde işlenmesi, sevkiyatı ve market kullanımı, geri kazanımı ve yeniden kullanımı ile bertarafına kadar olan sürece YDA adı verilmektedir. YDA analizinin çevresel etki değerlendirmesi aşamasının temelini oluşturan EoL hem açı̆̆a çıkan atık türlerinin bertarafi ve geri kazanımı/dönüşümü hem de alıcı ortamlarda oluşan çevresel etkileri ortaya koymaktadır. Bu noktada ise YDA analizinin bütününü incelemek ve EoL değerlendirmesini yapmak için uluslararası ISO 14040 ve ISO 14044 standartlarının belirlediği kriterler doğrultusunda çevresel etki düzeyleri ortaya konulmalıdır. EoL yaklaşımının en önemli avantajlarından biri diğer çevresel uygulamalarla karşılaştırılabilir nitelikte olmasıdır. Ayrıca, YDA analizinin son aşaması olarak kabul edilen EoL aynı zamanda alıcı ortamların risk analizini de sağlamış olmaktadır. Özellikle, açığa çıkan kirletici türlerinin oluşturduğu çevresel sorunların etki düzeylerini belirleyerek üretim aşamasında kullanılacak hammadde ve süreçlerin kontrolü sağlanmaktadır (EPA, 2010; TSE EN ISO 14040, 2007).

\section{Materyal ve Metot}

İki farklı deterjan içeriğine sahip olan atıksular bir çamaşır makinesinin normal kullanımı sonucunda elde edilmiştir (Şekil 2). Çamaşır makinesi atıksu örneklerinin öncelikle fiziksel, kimyasal ve bakteriyolojik parametreleri belirlenerek karakterizasyonu belirlendi. İncelenen parametreler arasında $\mathrm{pH}$, İletkenlik, Toplam Katı Madde (TKM), Askıda Katı Madde (AKM), Toplam Organik Karbon (TOK), Toplam Azot, Kimyasal Oksijen İhtiyacı (KOİ), MBAS, Fosfat, Nitrat, Florür, Bromür, Bromat, Klorür, Sülfat ve Nitrit bulunmaktadır. Tüm parametreler Standart Su ve Atıksu Metodu 2017 (APHA, 2017)'ye göre analiz edilmiştir. Atıksu karakterizasyonu için ham atıksuda mevcut anyon ve katyon analizleri gerçekleştirilmiş, ölçümler İyon Kromatografisi (ICS-1000, Dionex) ve endüktif olarak eşleşmiş plazma optik emisyon spektrometresi (ICP-OES Optima 2100 DV, Perkin Elmer, USA) cihazlarında gerçekleştirilmiştir. Numunelerin $\mathrm{pH}$ değerleri dijital HANNA pH 211 model pH metre ile ayarlanmıştır. KOİ analizleri SM-5220 D ve AKM analizleri SM-2540 C'ye göre gerçekleştirilmiştir. Deney yapılan anyonik yüzey aktif maddelerin konsantrasyonu SM-5540 C, Metilen Mavisi Emici Maddelerden (MBAS) modifiye edilen metoda göre yapılmıştır. Koliform sayımları steril koşullarda hazırlanan besi ortamı ve indikatörün iki film arasına işlenerek, direkt kullanıcının hizmetine sunulduğu $3 \mathrm{M}$ Petrifilm ile yapılmıştır. Atıksu örnekleri standart prosedürlere göre Ağustos 2020 ayında, 
Aksaray'daki bir evden toplanmış, pH ile iletkenlik gibi bazı parametrelerin ölçümleri atıksu deşarj hattında yerinde ölçülmüştür. Numuneler toplandıktan sonra, hemen niteliksel analiz için Aksaray Üniversitesi Mühendislik Fakültesi, Çevre
Mühendisliği Bölümü laboratuvarlarına aktarılmıştır. Numuneler, atıksudaki herhangi bir fiziksel-kimyasal değişikliği önlemek için $4^{\circ} \mathrm{C}$ 'de saklanmıştır.

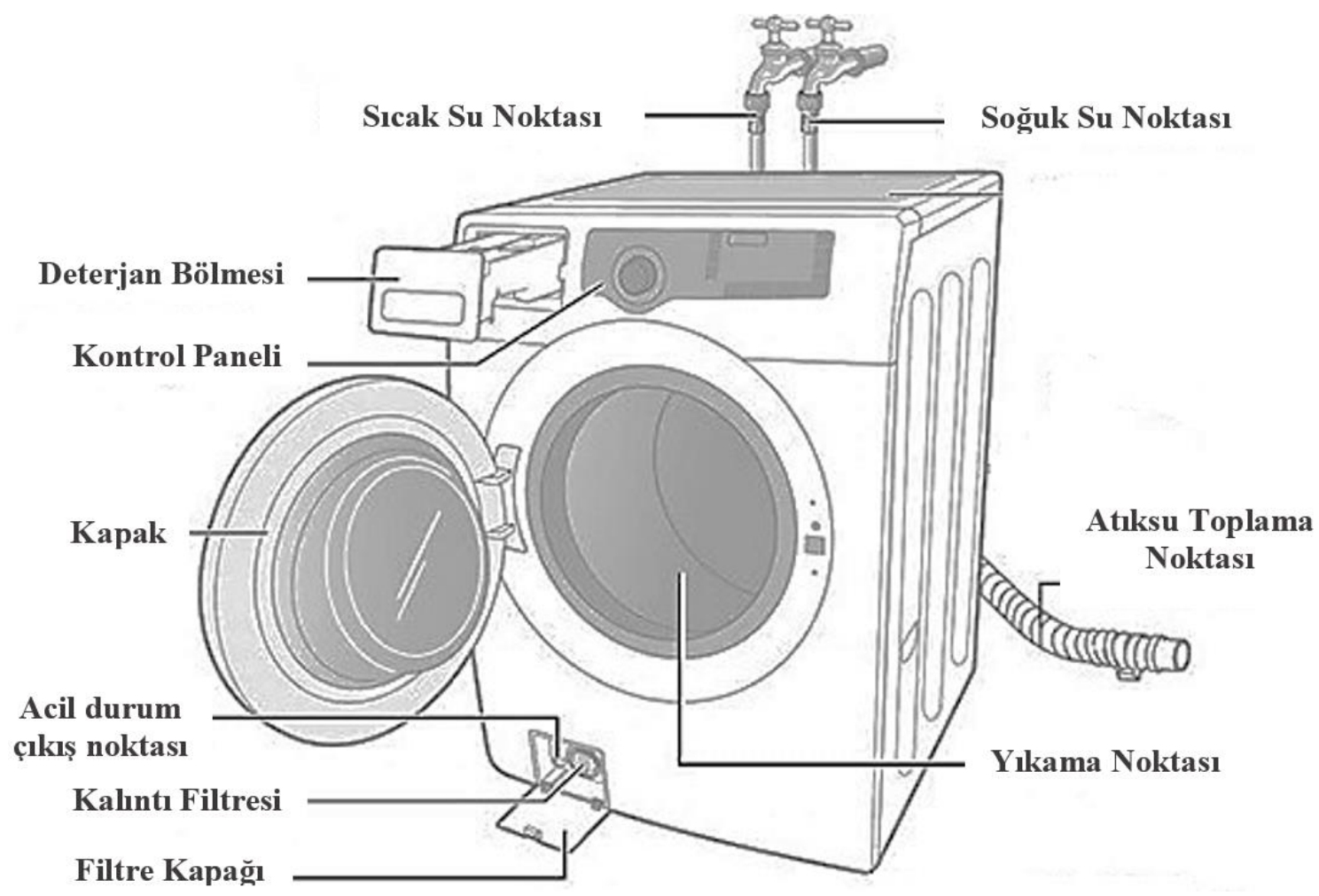

Şekil 2. Çamaşır Makinesi Su Giriş-Çıkış Yapıları ve Atıksu Toplama Noktası (URL-1, 2021)

\section{Araştırma Sonuçları ve Tartışma}

\subsection{Atıksu Karakterizasyonu}

Atıksu karakterizasyonu, kirleticilerin toplu olarak değerlendirilebildikleri anlamlı ve önemli parametreler bazında yapılmaktadır. Atıksu karakterizasyonu ülkeden ülkeye değişebileceği gibi, aynı ülke içerisinde de deterjanın türü, yıkama koşulları vd. parametrelere göre değişiklik göstermektedir. Evsel atıksuyun nispeten büyük bir kısmı çamaşır makinelerinden çıkan deterjanlı atıksudur. Çamaşır makineleri tipik olarak yıkama başına 50-200 L arasında atıksu üretebilirler (Burrows vd., 2006; Patil vd., 2020). Bu çalışma ile klasik ve bor içerikli deterjanların çamaşır makinesi atıksuyunun bileşimine katkısı da değerlendirilmiştir. Tablo 1'de literatürde araştırılmış çeşitli çamaşır makinesi atıksularının karakterizasyonu gösterilmiştir. Çamaşır makinesi atıksuları, arıtmayı zorlaştıran organik (sabunlar, deterjanlar, klorlu ve aromatik çözücüler ve biyolojik madde, yağlar, gres ve yağ) ve inorganik (ağır metaller, kum ve toprak tozu, metal iyonları ve parçacıklar) maddeler içerir. Tipik olarak KOİ, BOİ 5 ve TKM seviyesi sirasiyla 5000, 1300 ve 1000 mg/L'dir. Bazı durumlarda KOİ seviyesi $20000 \mathrm{mg} / \mathrm{L}$ 'ye kadar yükseldiği gözlenebilir (Lade \& Gbagba, 2018).

$\mathrm{Bu}$ çalışmadaki analizlere ait; kirletici konsantrasyon değerleri Tablo 2'de yer almaktadır. Yapılan analizler incelendiğinde çamaşır makinesi kaynaklı atıksularda özellikle KOİ konsantrasyonlarının oldukça yüksek ve çok değişken yapıya sahip olduğu görülmektedir. Buna göre bor içeriğine sahip deterjanın KOİ konsantrasyonu (2704 mg/L) diğer e-ISSN: 2148-2683 deterjanın KOİ değerine (6009 mg/L) göre daha düşük çıkmıştır. Tablo incelendiğinde bor içerikli ve normal deterjanlı atıksularda TOK parametresinin değerleri sirasıyla $729 \mathrm{mg} / \mathrm{L}$ ve $2058 \mathrm{mg} / \mathrm{L}$ olduğu görülmektedir. KOİ parametresinde olduğu gibi TOK içinde bor içerikli deterjanın atıksuyun kirlilik yükünü normal deterjana göre daha az arttırdığı tespit edilmiştir. Bor ve normal içerikli deterjan atıksularında $\mathrm{pH}$ değerleri sırasıyla 9.25 ve 8.35 ile bazik düzeyde bulunmuştur. Tablo 1 ve 2 'de verilen $\mathrm{pH}$ değerleri göz önünde bulundurulduğunda atıksu arıtma tesislerinde $\mathrm{pH}$ 'ın önemli bir etkisi olmadığı söylenebilir. Tablo 1'de, yapılan atıksu analizlerine ve EoL diyagramına göre bor içeriğine sahip deterjanın MBAS (104.1 mg/L) ve fosfat $(1.506$ $\mathrm{mg} / \mathrm{L})$ açısından diğer deterjana (MBAS=220.4 $\mathrm{mg} / \mathrm{L}$, Fosfat=8.863 mg/L) göre daha iyi olduğu açıkça ortaya konmuştur. Çamaşır makinesi atıksuyundaki ana bileşenlerden biri yüzey aktif maddedir (sürfaktan, lineer alkil benzen Sülfonat, sodyum laril sülfat). Yüzey aktif maddeler alıcı ortama verildiğinde, yüksek köpüklenme ve düşük oksijenasyon kapasitesi nedeniyle ortamın havalanmasını engelleyebilir, ayrıca arıtma tesislerinde de ek kirlilik yüküne neden olabilirler. Sürfaktanlar veya yüzey aktif maddeler, yağ ve suyun yüzey gerilimini azaltan kimyasallardır; deterjanlarda, sürfaktanlar kirin dışarı çıkmasına ve giysilerin veya temizlenen diğer nesnelerin dışında kalmasına yardımcı olur. 3M Petrifilm ile yapilan $e$-coli ve toplam koliform analizlerinde ise herhangi bir üreme gözlenmemiş olup, bu durum kanalizasyona direk verilen deterjanlı atıksuların sulama suyu olarak kullanılabilirliğini güçlendirmektedir. López Zavala \& Estrada (2016) yaptıkları çalışmada sıvı deterjanların, toz deterjanlara kıyasla atıksuya daha fazla KOİ, TOK ve daha az katı maddeler ile sürfaktan 
katkısında bulunduğunu tespit etmişlerdir. Ayrıca, önceki çalışmalar atıksuların arıtımı üzerine odaklanmış olup, Tablo 1 'de de görüldüğü gibi sınırlı sayıda karakterizasyon çalışmaları bulunmaktadır (Braga \& Varesche, 2014; Choobar vd., 2019; Lade \& Gbagba, 2018; Moura vd., 2019; Olabode.H vd., 2019; Siswoyo vd., 2019; Türkay vd., 2017).

Tablo 1. Literatürde Araştırılmış Çamaşır Makinesi Atıksularının Karakterizasyonu

\begin{tabular}{|c|c|c|c|c|c|c|c|c|c|c|}
\hline \multirow{2}{*}{ Parametre } & \multirow{2}{*}{ Birim } & \multicolumn{3}{|c|}{ (Lade \& Gbagba, 2018) } & \multirow{2}{*}{$\begin{array}{c}\text { (Olabode.H } \\
\text { vd., 2019) } \\
\text { Evsel }\end{array}$} & \multirow{2}{*}{$\begin{array}{c}\text { (Siswoyo } \\
\text { vd., } \\
\text { 2019) } \\
\text { Evsel }\end{array}$} & \multirow{2}{*}{$\begin{array}{c}\text { (Braga \& } \\
\text { Varesche, } \\
2014) \\
\text { Ticari }\end{array}$} & \multirow{2}{*}{$\begin{array}{c}\text { (Choobar } \\
\text { vd., } \\
\text { 2019) } \\
\text { Evsel }\end{array}$} & \multirow{2}{*}{$\begin{array}{l}\text { (Moura } \\
\text { vd., } \\
2019 \text { ) } \\
\text { Evsel }\end{array}$} & \multirow{2}{*}{$\begin{array}{c}\text { (Türkay } \\
\text { vd., } \\
2017) \\
\text { Evsel }\end{array}$} \\
\hline & & Evsel & Endüstriyel & Hastane & & & & & & \\
\hline İletkenlik & $\mu \mathrm{S} / \mathrm{cm}$ & $190-1400$ & $640-3000$ & $808-2000$ & 682 & - & - & 7520 & - & 270 \\
\hline TKM & $\mathrm{mg} / \mathrm{L}$ & $400-6000$ & 420 & $455-800$ & 767 & - & 80 & 5190 & 84 & - \\
\hline AKM & $\mathrm{mg} / \mathrm{L}$ & $200-987$ & $45-68$ & $66-71$ & - & - & 10 & 240 & - & - \\
\hline $\mathrm{BOI}_{5}$ & $\mathrm{mg} / \mathrm{L}$ & $48-1200$ & $218-9810$ & $44-50$ & 210 & - & - & 1190 & - & 484 \\
\hline Florür & $\mathrm{mg} / \mathrm{L}$ & - & - & - & 21.3 & - & - & - & - & 0.78 \\
\hline Klorür & $\mathrm{mg} / \mathrm{L}$ & - & - & - & 135.33 & - & - & - & - & 23.80 \\
\hline Nitrat & $\mathrm{mg} / \mathrm{L}$ & - & - & - & 36.0 & - & - & - & - & 0.73 \\
\hline Fosfat & $\mathrm{mg} / \mathrm{L}$ & $4-27.6$ & 3.43 & $10.8-167$ & 17.5 & 2 & 94.6 & - & - & 64.76 \\
\hline Sülfat & $\mathrm{mg} / \mathrm{L}$ & - & - & - & 40.2 & - & 21.1 & - & 535 & 0.70 \\
\hline
\end{tabular}

Tablo 2. Farklı Deterjan İçeriğine Sahip Çamaşır Makinesi Atıksularının Karakterizasyonu

\begin{tabular}{|c|c|c|c|c|}
\hline Parametre & Birim & Ham Su & $\begin{array}{c}\text { Normal Deterjan } \\
\text { Atıksuyu }\end{array}$ & $\begin{array}{c}\text { Bor İçerikli Deterjan } \\
\text { Atıksuyu }\end{array}$ \\
\hline $\mathrm{pH}$ & - & 6.97 & 8.35 & 9.25 \\
\hline İletkenlik & $\mu \mathrm{S} / \mathrm{cm}$ & 716 & 1275 & 4140 \\
\hline TKM & $\mathrm{mg} / \mathrm{L}$ & - & 3956 & 7628 \\
\hline AKM & $\mathrm{mg} / \mathrm{L}$ & $<11.93^{*}$ & 353 & 753 \\
\hline Toplam Azot & $\mathrm{mg} / \mathrm{L}$ & 16.15 & 270.4 & 157.1 \\
\hline TOC & $\mathrm{mg} / \mathrm{L}$ & 58.57 & 2058 & 729 \\
\hline KOİ & $\mathrm{mg} / \mathrm{L}$ & $<22.87^{*}$ & 6009 & 2704 \\
\hline MBAS & $\mathrm{mg} / \mathrm{L}$ & $<0.015^{*}$ & 220.4 & 104.1 \\
\hline Florür & $\mathrm{mg} / \mathrm{L}$ & 0.3045 & 0.3325 & 12.1202 \\
\hline Klorür & $\mathrm{mg} / \mathrm{L}$ & 73.5958 & 156.7908 & 243.2966 \\
\hline Bromür & $\mathrm{mg} / \mathrm{L}$ & 0.9296 & 0.1618 & 6.1647 \\
\hline Bromat & $\mathrm{mg} / \mathrm{L}$ & - & - & 0.2894 \\
\hline Nitrit & $\mathrm{mg} / \mathrm{L}$ & - & - & 4.1002 \\
\hline Nitrat & $\mathrm{mg} / \mathrm{L}$ & 5.9096 & 4.2368 & 6.6740 \\
\hline Fosfat & $\mathrm{mg} / \mathrm{L}$ & 0.0062 & 8.8627 & 1.5064 \\
\hline Sülfat & $\mathrm{mg} / \mathrm{L}$ & 42.4679 & 8.2357 & 1.4673 \\
\hline$e-$ coli & $\mathrm{KOB} / 100 \mathrm{~mL}$ & - & - & - \\
\hline Toplam koliform & $\mathrm{KOB} / 100 \mathrm{~mL}$ & - & - & - \\
\hline
\end{tabular}

\section{2. Çevresel Etkiler ve Kirleticilerin Potansiyelleri}

Deterjanlar, çamaşır ve bulaşık makinesi deterjanları da dâhil olmak üzere çok çeşitli endüstriyel ve ev temizlik uygulamalarında kullanılır. Evden gelen atıksu akışına salınan bu deterjanlar, geniş kapsamlı çevresel etkilere neden olabilir. Çalışmada kullanılan her iki tür deterjan içeriğine sahip çamaşır makinesi atıksularının olası çevresel etkileri daha önceki araştırmalar doğrultusunda ve yapılan atıksu karakterizasyon analizleri sonucunda değerlendirilmiştir. Elde edilen sonuçlara göre altında çevresel riskler ve oluşan potansiyel kirlilikler YDA ve EoL diyagramları ile gösterilmiştir (TSE EN ISO 14040, 2007). Evde giysi yıkamanın her bir aşamasıyla ilişkili çevresel risk kategorisine göre etkilerin dağılımı, YDA ve EoL diyagramları temel alındığında (SimaPro ve CalcPlot3D modelleme) Şekil 3'de gösterilmektedir. EPA verilerine göre (EPA, 2010);

- 1 kg giysiyi yıkarken su tüketimi 30.4 L

- $1 \mathrm{~kg}$ kuru giysinin ötrofikasyon potansiyeli $1.17 \mathrm{~g} \mathrm{PO}_{4}$

- $1 \mathrm{~kg}$ giysinin yıkanması ile oluşan sera gazı emisyonları $0.21 \mathrm{~kg} \mathrm{CO}$ - eşdeğerindedir

- $1 \mathrm{~kg}$ giysinin yıkanmasından elde edilen enerji tüketimi $2.476 \mathrm{~kJ}$ eşdeğerinde olup bu sayısal verilerle yüzde cinsinden çevresel risk potansiyelleri ortaya konabilmektedir. 


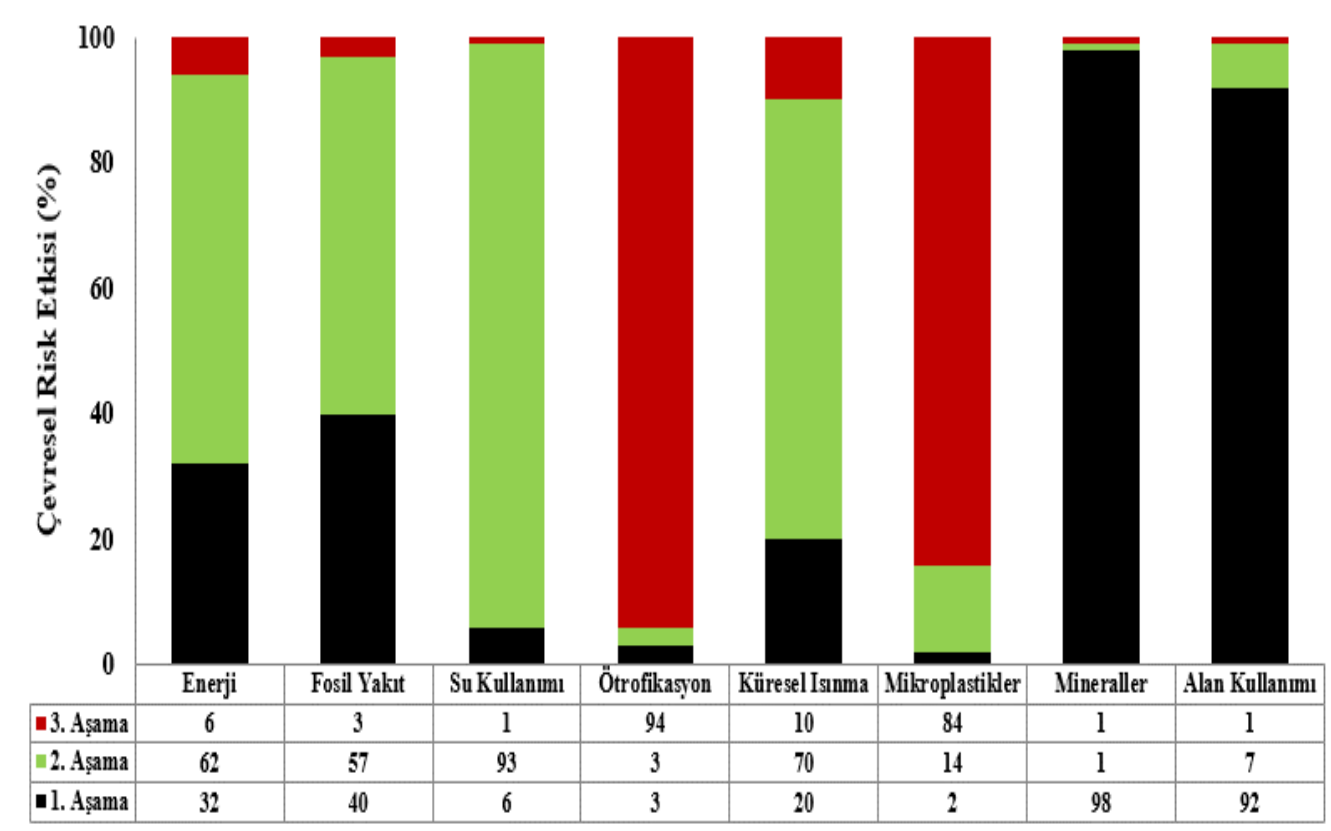

Şekil 3. Üç Aşamalı Çevresel Etki Kategorilerine Göre Yüzde Değişimleri

Çalışmamızın amacı, $1 \mathrm{~kg}$ giysiyi çamaşır makinesinde yıkama sonucunda ve yıkama aşamasından önceki kademeler için yaşam döngüsü etkilerini anlamak ve atıksuyun genel yapısını ortaya çıkarmaktır. Bu çalışma sırasında tanımlanan ev tipi çamaşır yıkamanın yaşam döngüsü (YDA diyagramı) ve çevresel sonuçları (EoL diyagramı) Şekil 4 ve 5'de görülebilir. $\mathrm{Bu}$ diyagramlar incelendiğinde YDA değerlendirmesinin 3 aşamadan oluşmaktadır. Birinci aşama yıkama işleminde kullanılan ana ürünlerin (deterjan, çamaşır makinesi, soda-kireç, yumuşatıcı ve ağartıcı malzemeler vb.) üretimi, dağıtımı ve paketlenmesi ile ilgili süreçleri içermektedir. İkincisi kullanım aşaması olup evlerde düzenli olarak çamaşır yıkamak için tükettikleri tüm kaynakları su, deterjan ve enerji dahil olmak üzere kullanımlarını kapsamaktadır. Üçüncü ve son aşama ise, çamaşır makinesi ve diğer ekipmanlar, deterjanlar ve açığa çıkan deterjanlı atıksuları kapsayan üretilen tüm malzemelerin ve kimyasalların bertarafi ve işlenmesini ilgilendirmektedir. Deterjan kullanımının iki ana şekilde etkileri gerçekleşmektedir. Birincisi deterjan ve diğer yan ürünlerin üretimiyle ilişkili çevresel etkiler ve ikinci olarak çamaşır makinesi kullanımından kaynaklanan deterjan içerikli atıksu ile bağlantılı çevresel etkilerdir. Giagnorio vd. (2017) yaptıkları çalışmada çamaşır yıkama endüstrisinde kullanılan deterjanların çevresel etkilerinin YDA modeli ile genel değerlendirilmesini gerçekleştirmişlerdir. $\mathrm{Bu}$ çalışma ile çamaşır yıkama endüstrisinden kaynaklanan ekosistem sorunlarında temel rolün deterjanlarda olduğu ortaya konmuştur. Ötrofikasyon potansiyelinin yaklaşık \% 94 gibi yüksek bir oranı, özellikle yıkama döngüsünden üretilen atıksuyun yapısında yer alan deterjanların içeriğinden kaynaklanmaktadır. Jardak et al. (2016)'ya göre, sürfaktanların sucul ve karasal ekosistemlerde davranışları oldukça kompleks yapıda gerçekleşmekte ve çevresel etkileri de (ötrofikasyon gibi) ağır olmaktadır. Lopes vd. (2019) yaptıkları diğer bir araştırma da ise ev tipi deterjanların Poecilia reticulata üzerindeki davranışsal değişimleri ve toksisitesi izlenmiştir. Enerji kullanımının çoğu kullanım, yani yıkama aşamasında gerçekleşmektedir. Özellikle, mikroplastikler ve ötrofikasyon gibi en belirgin kirlilik durumu olarak karşımıza çıkmaktadır. Ev tipi çamaşır makinelerinden her yıkama sonucunda mikroplastik (lif, elyaf ve giysi parçacıkları vb.) kirleticilerin alıcı ortama yayılması, sentetik tekstil ürünlerinin yapısından (plastik lifler vb.) ve yıkama koşullarından ileri gelmektedir. Mikroplastiklerin deniz ve tatlı su ortamları başta olmak üzere çok çeşitli su ortamlarında (plajlar, göl, nehir, sediment vb.) olabileceği yapılan araştırmalar ile ortaya konmuştur. Özellikle tekstil ürünlerinin (kıyafet, halı, kilim, perde, çarşaf, yastık kılıfı vb.) yıkanması sonucunda mikroplastik boyutlu liflerin ve çeşitli elyafların (pamuk-yün, naylon, polyester-pamuk vb.) salınması, potansiyel bir mikroplastik kaynağı olarak küresel ölçekte yaygın bir şekilde rapor edilmiştir (Barrows vd., 2018; De Falco vd., 2019; Geyer vd., 2017; Kogawa vd., 2017; McIlwraith vd., 2019; Prata, 2018). Ancak çamaşır makinesi atıksularından kaynaklanan mikroplastik potansiyelinin bilim insanları tarafindan göreceli olduğunu da belirtmek gerekmektedir. Çünkü çoğu bilim insanı bu tarz deşarjlardan kaynaklı mikroplastik kirliliğinin diğer kaynaklara göre düşük oranda kalacağını düşünmektedirler. Son yıllarda yapılan araştırmalar giysilerin yıkanması sonucu oluşan atıksuların, potansiyel olarak önemli bir mikroplastik kaynağı olduğunu ortaya koymaktadır. Yıkama sonrası tekstil ürünlerindeki lif ve elyafları içeren çamaşır makinelerinden çıkan atıksular kanalizasyon sistemleri ile arıtma tesislerine ulaşmaktadır (Dris vd., 2015). Lif ve elyaf malzemelerin boyutlarının küçük ölçekli olmasından dolayı sistemden kaçışlarla alıcı ortamlara geçebilirler. Deterjan türü ve yıkama koşulları da bunların atıksuya geçişini hızlandırabilmektedir. Çoğu tekstil ürününde yıkama özellikleri manuel ve çamaşır makinesi için belirtilmiş olup bu koşullara uyulmadığında lif ve elyafların atıksudaki yoğunlukları da artmaktadır. Ayrica bu malzemeler biyolojik olarak parçalanamadığından arıtma çamurunda birikim gösterecek ve çevreye dağılım olabilecektir (Dris vd., 2015; Gallagher vd., 2016; Napper vd., 2015; Napper \& Thompson, 2016). Gerçekten de, birçok çalışma deniz habitatlarında mikroplastik birikimini bildirmiştir. Sucul ortamlarda mikroplastik ve lif birikimi için kaynaklardan birinin yıkama sırasında giysilerden dökülen lifler olduğundan şüphelenilmektedir (Ivar Do Sul \& Costa, 2014). Özellikle, bazı bilim insanları ev tipi çamaşır makinesi atıksularının "mikroplastik" kirliliğinin ana kaynağı olduğunu bildirmişlerdir. Sucul ortamlarda mikroplastiklerin kuşlar ve kaplumbağalar tarafindan yutulması literatürde belirtilmiş ve deniz kuşu türlerinin \% 40'ından fazlasının plastik yediği bilinmektedir (Durán vd., 2018). 


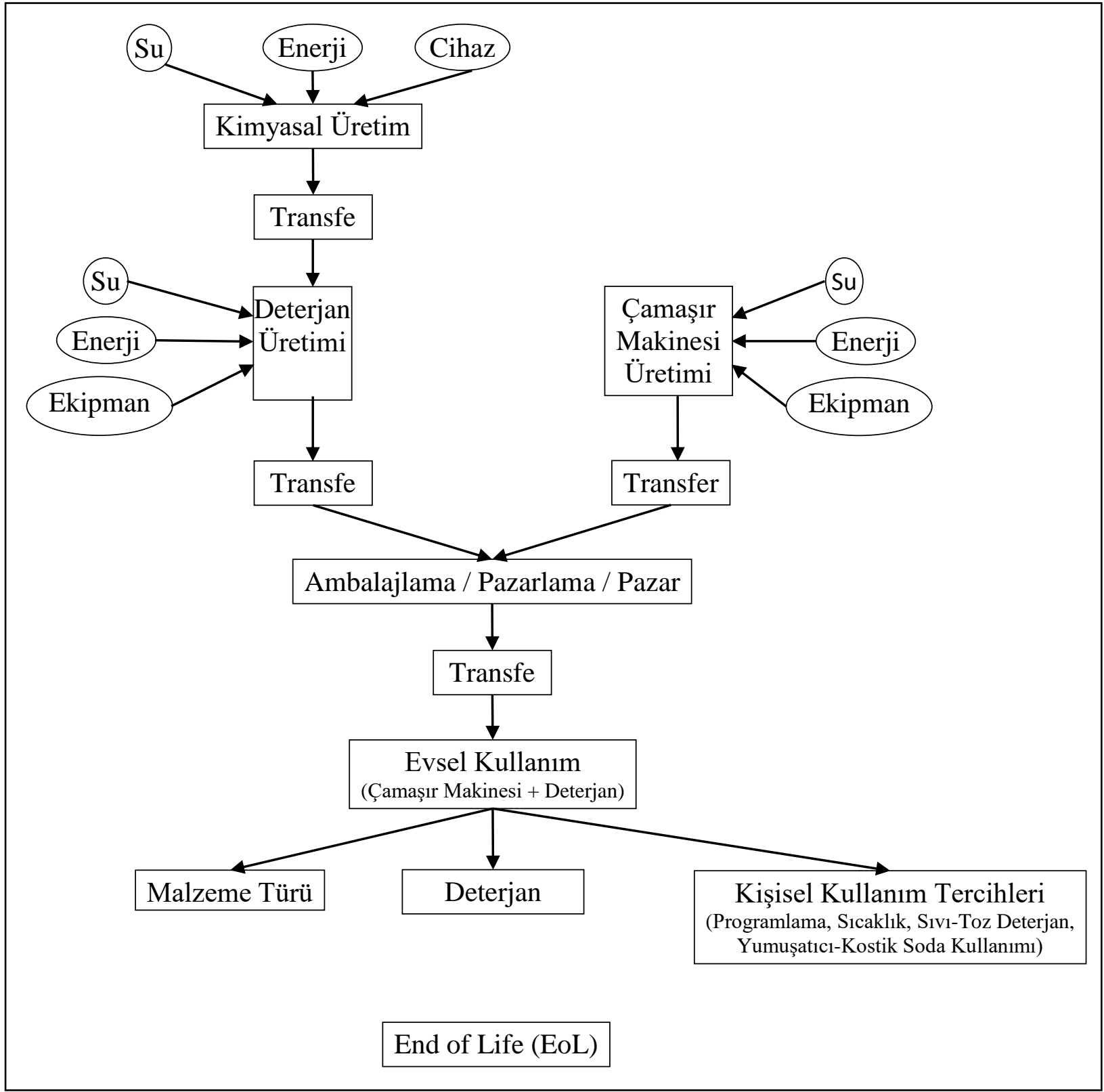

Şekil 4. ÜÇ Aşamalı YDA Diyagramı 


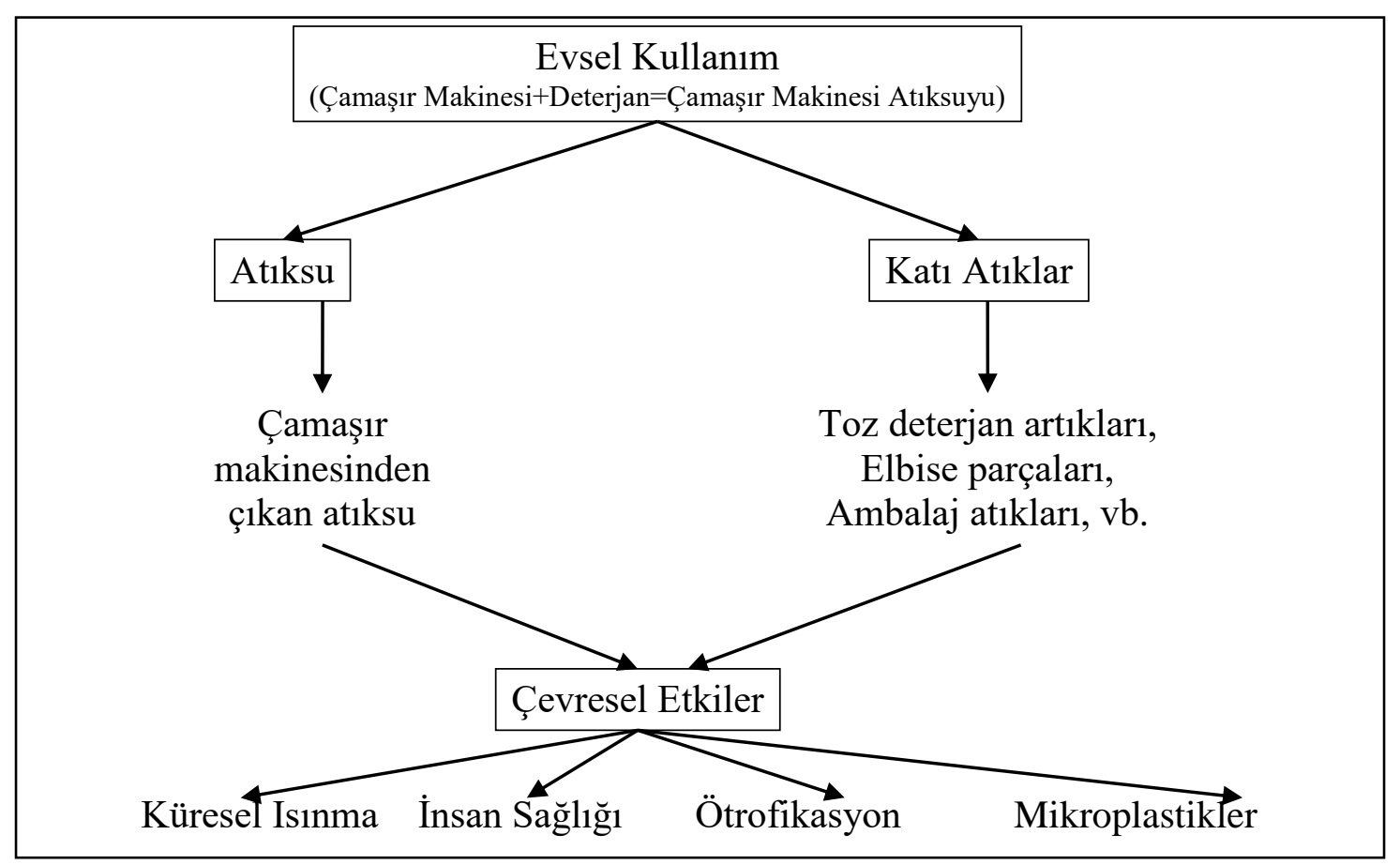

Şekil 5. Çamaşır Atıksularının ve Katı Atıklarının Çevresel EoL Diyagramı

Ötrofikasyon ise, çözünmüş oksijen seviyesinin kaybı nedeniyle su ekosistemini bütünleşik olarak doğrudan etkileyen ciddi su kirliliği göstergelerinden biridir. Balıkların erken ve nispeten daha hızlı ölümüne yol açmakta ve böylece göl ve diğer su ortamlarının su kalitesini bozmaktadır. Evsel deterjanlar, kullanımları sonucunda su kütlelerinde ve arıtma tesislerinde ana antropojenik fosfor kaynağı olarak karşımıza çıkmaktadır. Deterjanlar normalde sürfaktanlar ve yapıcı olarak nitelendirilen polifosfat tuzlarından oluşmaktadır (Mousavi \& Khodadoost, 2019). Evsel atıksulardaki sürfaktan konsantrasyonları için bildirilen değerler 3-21 mg/L arasında değişmektedir (Patil vd., 2020). Düşük konsantrasyonlarda sürfaktanlar, alıc1 su ortamlarında büyük miktarda köpük üretmektedirler. Bu durum ise biz insanlar için toksik değildir, ancak sucul ekosistem üzerinde önemli bir etki yapmaktadır. Özellikle, sudaki oksijen emilim oranını düşürerek ortamın anaerobik koşullara dönmesine yol açmaktadır. Deterjan içeriğine sahip atıksulardan kaynaklanan ötrofikasyon, su ekosisteminin zaman içerisinde yaşlanma sürecini hızlandırdığından arıtma tesislerinde deterjan içeriği yüksek yüklerde daha iyi arıtım sağlanmalıdır. Ayrıca bu kirliliğin balıkçılık ve su canlıları üzerinde olumsuz etkileri de olmaktadır. Çünkü doğal ekosistem bozulduğunda canlıların yaşam alanları sınırlanmakta ve sonuç olarak farklı yaşam alanları ortaya çıkmaktadır. Bu sürfaktan ve fosfat içeriğine sahip deterjanlara doğal ekosistemin maruz kalması, çevresel stres, üreme ve büyümede bozuklar gibi hayati fonksiyonları ve süreçleri etkileyerek sucul canlılığın etkinliğini azaltabilir. Azalan etkinlik ile birlikte fosfatı besin maddesi olarak kullanan algler ortamda aşırı büyümeye başlarlar. Su ekosistemi aerobik şartlardan anaerobik ortama doğru değişir. Bu çevresel etkilerin dışında katı atık grubunda ise paketleme sürecinde karşılaşılmaktadır. EPA'ya göre çamaşır makinesi deterjanları genellikle tekrar kullanılamayan ve geri dönüştürülemeyen plastik kaplarda evlere ulaşmaktadır. Deterjan bazlı ev ürünleri tüketicilerin önemli bir kısmı tarafindan haftalık olarak satın alındığında, düzenli depolama alanlarına giden deterjan ambalajı hacmi muazzam bir çevresel etki oluşturmaktadır.

\section{Sonuç}

Bir atıksu için kirlilik yükü potansiyeli belirlenmeden önce yapılacak ilk ve en önemli aşama o atıksuyun karakterizasyonunu ortaya koymaktır. Atıksuyun karakterizasyonu arıtma tesisine ulaşacak kirlilik yükü seviyesi hakkında fikir verebilir. YDA deterjan ve çamaşır makinesi üretimi ve bunların kullanımı sonucu salınan atıksuların çevresel etki düzeyini tespit etmede kullanılan yöntemlerden biridir. YDA ve EoL diyagramlarına göre küresel 1sınma, ötrofikasyon insan toksisitesi ve ekotoksisite ile mikroplastikler deterjan bazlı çamaşır makinesi atıksularının temel etki kategorileridir. Etki kategorileri içinde en çok mikroplastikler ve ötrofikasyon potansiyeli gözlenmektedir. Ötrofikasyonun ana nedeni olan fosfor ve bileşenleri iki deterjan grubunda da ölçülmüş ve yüksek konsantrasyonlar elde edilmiştir. Çalışmada yapılan deneyler sonucunda her iki deterjan türünün ham suyun fosfat içeriğini arttırdığı tespit edilmiştir. Uluslararası platformlarda deterjanların üretiminde kullanılan ana bileşen ve temizleme seviyesini etkileyen madde sürfaktanlardır. Ayrıca, yardımcı bazı aktive edici ürünler (ağartıcılar, köpük ajanları, stabilizatör, parfüm ajanları, vd.) ve yapıcı olarak adlandırılan fosfat türleri kullanılmaktadır. Deterjanlarda ve diğer kişisel bakım ürünlerinde yer alan fosfat bileşikleri, $\mathrm{pH}$ 'ı korumak için de ürünlere dahil edilmektedir. Temizlik ürünlerinde kullanılan birçok fosfat (Ortofosfatlar $\left(\mathrm{PO}_{4}^{-3}\right)$, Pirofosfatlar $\left(\mathrm{P}_{2} \mathrm{O}_{7}{ }^{-4}\right)$, Tripolifosfatlar $\quad\left(\mathrm{P}_{3} \mathrm{O}_{10}{ }^{-5}\right)$, Polifosfatlar $\left.\quad\left(\mathrm{P}_{\mathrm{n}} \mathrm{O} 3_{\mathrm{n}+1}{ }^{-(\mathrm{n}+2)}\right)\right)$ muhteviyatı sucul ekosistemlerde konsantrasyonu artırmaktadır. $\mathrm{Bu}$ nedenle, son yıllarda yeni nesil deterjanlarda fosfat yerine zeolit, yağlar vb. doğal materyaller tercih edilmektedir. YDA analizi sonucunda son nokta olan EoL diyagramında yikama işlemi kaynaklı atıksular ve içeriğinde bulunan deterjanlar arasında karmaşık bir etkileşim olduğu söylenebilir. Yaşam döngüsü analizi, çevresel riskleri tanımlamada uygulanan bir çevresel etki değerlendirme yöntemidir. Sonuçta, yapılan atıksu analizlerine ve EoL diyagramına göre bor içeriğine sahip deterjanın yüzey aktif madde (MBAS) $(104.1 \mathrm{mg} / \mathrm{L})$ ve fosfat $(1.506 \mathrm{mg} / \mathrm{L})$ açısından diğer deterjana $(\mathrm{MBAS}=220.4 \mathrm{mg} / \mathrm{L}$, fosfat $=8.863 \mathrm{mg} / \mathrm{L}$ ) göre daha iyi olduğu ortaya konmuştur. 


\section{Kaynakça}

APHA. (2017). Standard Methods for the Examination of Water and Wastewater 23 edition. I: American Public Health Association (APHA). American Water Works Association, Water Pollution Control Federation, \& Water Environment Federation.

Ashfaq, M. Y., \& Qiblawey, H. (2018). Laundry wastewater treatment using ultrafiltration under different operating conditions. AIP Conference Proceedings, 2022, Article 020002. https://doi.org/10.1063/1.5060682

Barrows, A. P. W., Cathey, S. E., \& Petersen, C. W. (2018). Marine environment microfiber contamination: Global patterns and the diversity of microparticle origins. Environmental Pollution, 237, 275-284. https://doi.org/10.1016/j.envpol.2018.02.062

Bianchetti, G. O., Devlin, C. L., \& Seddon, K. R. (2015). Bleaching systems in domestic laundry detergents: A review. RSC Advances, 5(80), 65365-65384. https://doi.org/10.1039/c5ra05328e

Boulay, A. M., Bayart, J. B., Bulle, C., Franceschini, H., Motoshita, M., Muñoz, I., Pfister, S., \& Margni, M. (2015). Analysis of water use impact assessment methods (part B): applicability for water footprinting and decision making with a laundry case study. International Journal of Life Cycle Assessment, 20(6), 865-879. https://doi.org/10.1007/s11367-015-0868-9

Braga, J. K., \& Varesche, M. B. A. (2014). Commercial Laundry Water Characterisation. American Journal of Analytical Chemistry, 5(1), 8-16. https://doi.org/10.4236/ajac.2014.51002

Burrows, J., Crawford, R. J., Norris, P. J., \& Thorley, D. C. (2006). Laundry detergent composition (Patent $\mathrm{Nr}$. US7078373B2).

https://patents.google.com/patent/US7078373B2/en

Choobar, B. G., Shahmirzadi, M. A. A., Kargari, A., \& Manouchehri, M. (2019). Fouling mechanism identification and analysis in microfiltration of laundry wastewater. Journal of Environmental Chemical Engineering, 7(2), Article 103030. https://doi.org/10.1016/j.jece.2019.103030

Dai, M., Guo, J., Xue, X., \& Feng, Y. (2019). Preparation and Investigation of High-Efficiency Antibacterial Liquid Dishwashing Detergent. Transactions of Tianjin University, 25(4), 322-329. https://doi.org/10.1007/s12209-019-00187$\mathrm{X}$

De Falco, F., Di Pace, E., Cocca, M., \& Avella, M. (2019). The contribution of washing processes of synthetic clothes to microplastic pollution. Scientific Reports, 9(1), Article 6633. https://doi.org/10.1038/s41598-019-43023-X

Dris, R., Gasperi, J., Rocher, V., Saad, M., Renault, N., \& Tassin, B. (2015). Microplastic contamination in an urban area: A case study in Greater Paris. Environmental Chemistry, 12(5), 592-599. https://doi.org/10.1071/EN14167

Durán, F. E., de Araújo, D. M., do Nascimento Brito, C., Santos, E. V., Ganiyu, S. O., \& Martínez-Huitle, C. A. (2018). Electrochemical technology for the treatment of real washing machine effluent at pre-pilot plant scale by using active and non-active anodes. Journal of Electroanalytical Chemistry, $\quad 818, \quad 216-222$. https://doi.org/10.1016/j.jelechem.2018.04.029

EPA. (2010). Life Cycle Assessment of Clothes Washing Options for City West Water's Residential Customers.

Gallagher, A., Rees, A., Rowe, R., Stevens, J., \& Wright, P.
(2016). Microplastics in the Solent estuarine complex, UK: An initial assessment. Marine Pollution Bulletin, 102(2), 243-249. https://doi.org/10.1016/j.marpolbul.2015.04.002

Geyer, R., Jambeck, J. R., \& Law, K. L. (2017). Production, use, and fate of all plastics ever made. Science Advances, 3, Article e1700782. http://advances.sciencemag.org/

Giagnorio, M., Amelio, A., Grüttner, H., \& Tiraferri, A. (2017). Environmental impacts of detergents and benefits of their recovery in the laundering industry. Journal of Cleaner Production, 154, 593-601. https://doi.org/10.1016/j.jclepro.2017.04.012

Ivar Do Sul, J. A., \& Costa, M. F. (2014). The present and future of microplastic pollution in the marine environment. I: Environmental Pollution, 185, 352-364. https://doi.org/10.1016/j.envpol.2013.10.036

Jardak, K., Drogui, P., \& Daghrir, R. (2016). Surfactants in aquatic and terrestrial environment: occurrence, behavior, and treatment processes. Environmental Science and Pollution Research, 23(4), 3195-3216. https://doi.org/10.1007/s11356-015-5803-X

Kogawa, A. C., Cernic, B. G., do Couto, L. G. D., \& Salgado, H. R. N. (2017). Synthetic detergents: 100 years of history. I: Saudi Pharmaceutical Journal, 25(6), 934-938. https://doi.org/10.1016/j.jsps.2017.02.006

Lade, O., \& Gbagba, Z. (2018). Sustainable water supply: Potential of recycling laundry wastewater for domestic use. Journal of Civil Engineering and Environmental Sciences, 4(2), 056-060. https://doi.org/10.17352/2455-488x.000029

Lopes, J. V. S. R., Young, R. J., \& de Azevedo, C. S. (2019). Effects of the neutral household detergent on the behaviour and personality of guppy Poecilia reticulata (Peters, 1859) (Osteichthyes: Poeciliidae). Acta Ethologica, 22, 113-123. https://doi.org/10.1007/s10211-019-00313-x

López Zavala, M. Á., \& Estrada, E. E. (2016). The contribution of the type of detergent to domestic laundry graywater composition and its effect on treatment performance. Water, 8(5), 214. https://doi.org/10.3390/w8050214

McIlwraith, H. K., Lin, J., Erdle, L. M., Mallos, N., Diamond, M. L., \& Rochman, C. M. (2019). Capturing microfibers marketed technologies reduce microfiber emissions from washing machines. Marine Pollution Bulletin, 139, 40-45. https://doi.org/10.1016/j.marpolbul.2018.12.012

Moura, A. G. L., Centurion, V. B., Okada, D. Y., Motteran, F., Delforno, T. P., Oliveira, V. M., \& Varesche, M. B. A. (2019). Laundry wastewater and domestic sewage pilotscale anaerobic treatment: Microbial community resilience regarding sulfide production. Journal of Environmental Management, $\quad 251, \quad$ Article 109495. https://doi.org/10.1016/j.jenvman.2019.109495

Mousavi, S. A., \& Khodadoost, F. (2019). Effects of detergents on natural ecosystems and wastewater treatment processes: a review. Environmental Science and Pollution Research, 26, 26439-26448. https://doi.org/10.1007/s11356-019-05802-x

Napper, I. E., Bakir, A., Rowland, S. J., \& Thompson, R. C. (2015). Characterisation, quantity and sorptive properties of microplastics extracted from cosmetics. Marine Pollution Bulletin, 99(1-2),

178-185. https://doi.org/10.1016/j.marpolbul.2015.07.029

Napper, I. E., \& Thompson, R. C. (2016). Release of synthetic microplastic plastic fibres from domestic washing machines: Effects of fabric type and washing conditions. Marine Pollution Bulletin, 112(1-2), 39-45. https://doi.org/10.1016/j.marpolbul.2016.09.025 
Olabode.H, O., Idongesit.A, E., Yahaya, Y., Yahaya.M, A., Yakubu, S., \& Fatimo.T, B. (2019). Treatment of Domestic Laundry Waste-Water with Analar Grade Activated Charcoal and Adsorption Models with Two (Langmuir \& Freundlich) and Three (Elovich) Parameters Isotherms. International Journal of Creative and Innovative Research in All Studies, 2(6), 31-38.

Ordu, M. (2017). Çevresel Etkinin Zaman İçerisindeki Değişiminin Yaşam Döngüsü Analiziyle Değerlendirilmesi: Bursa Organize Sanayi Bölgesi Su Üretim Tesisi Örneği. Yüksek Lisans Tezi, Uludağ Üniversitesi, Fen Bilimleri Enstitüsü, 90s.

Patil, V. V., Gogate, P. R., Bhat, A. P., \& Ghosh, P. K. (2020). Treatment of laundry wastewater containing residual surfactants using combined approaches based on ozone, catalyst and cavitation. Separation and Purification Technology, 239, Article 116594. https://doi.org/10.1016/j.seppur.2020.116594

Prata, J. C. (2018). Microplastics in wastewater: State of the knowledge on sources, fate and solutions. Marine Pollution Bulletin, 129(1), 262-265. https://doi.org/10.1016/j.marpolbul.2018.02.046

Siswoyo, E., Utari, A. W., \& Mungkari, L. G. N. (2019). Adsorption Combined Phytoremediation System for Treatment of Laundry Wastewater. MATEC Web of Conferences, 280, Article 05002. https://doi.org/10.1051/matecconf/201928005002
Tripathi, S. K., \& Khan, U. (2019). Removal efficiency and adsorption aspects of sand \& bagasse for residual surfactant from laundry wastewater (LW). International Journal of Recent Technology and Engineering, 8(3), 7804-7808. https://doi.org/10.35940/ijrte.C6353.098319

TSE EN ISO 14040. (2007). Çevre yönetimi-Hayat boyu değerlendirme-Illkeler ve çerçeve (ISO 14040:2006).

Türkay, Ö., Barışcı, S., \& Sillanpää, M. (2017). E-peroxone process for the treatment of laundry wastewater: A case study. Journal of Environmental Chemical Engineering, 5(5), 4282-4290. https://doi.org/10.1016/j.jece.2017.08.012

URL-1. (2021). Washing Machine Will Not Start - What To $\begin{array}{lllll}\text { Check } & - & \text { How } & \text { To } & \text { Fix. }\end{array}$ https://removeandreplace.com/2015/04/10/washingmachine-will-not-start-what-to-check-how-to-fix/ Erişim tarihi: 15.01.2021

Veli, S., Arslan, A., Gülümser, Ç., Topakkaya, E., Kurtkulak, H., Zeybek, Ş., Dimiglo, A., \& İşgören, M. (2019). Advanced Treatment of Pre-treated Commercial Laundry Wastewater by Adsorption Process: Experimental Design and Cost Evaluation. Journal of Ecological Engineering, 20(10), 165-171. https://doi.org/10.12911/22998993/113151

Yapıcıŏ̆lu, P., \& Demir, Ö. (2017). Çamur Arıtımının Yaşam Döngüsü Değerlendirmesi-Genel Bakış. Harran Üniversitesi Mühendislik Dergisi, 2, 78-92. 